\title{
A Modelling Approach for Railway Overhead Line Equipment Asset Management
}

\author{
Paul Kilsby, Rasa Remenyte-Prescott and John Andrews \\ Asset Management Section, Resilience Engineering Research Group, University of Nottingham, \\ University Park, Nottingham, NG7 2RD, UK
}

\begin{abstract}
The Overhead Line Equipment (OLE) is a critical sub-system of the $25 \mathrm{kV}$ AC overhead railway electrification system. If OLE asset management strategies can be evaluated using a whole lifecycle cost analysis that considers degradation processes and maintenance activities of the OLE components, the investment required to deliver the level of performance desired by railway customers and regulators can be based on evidence from the analysis results. A High Level Petri Net (HLPN) model, proposed in this paper, is used to simulate the degradation, failure, inspection and maintenance of the main OLE components and to calculate various statistics, associated with the cost and reliability of the system over its lifecycle. The HLPN considers all the main OLE components in a single model and it can simulate fixed frequency inspections and condition-based maintenance regimes. In order to allow the relevant processes to be modelled accurately and efficiently, the HLPN features are used, such as specific data about individual components is taken account of in the general model. The HLPN, developed using international standards, is described in detail and a framework of its analysis for reliability and lifecycle cost evaluation is proposed. In this novel whole system model different OLE component types and their instances on a line are modelled simultaneously, and the dependencies are considered in terms of opportunistic inspection and maintenance. An example HLPN for the catenary wire is used to illustrate the model, and an application of the methodology for whole lifecycle cost evaluation of a two-mile OLE line is presented.
\end{abstract}

\section{Introduction}

Individual Overhead Line Equipment (OLE) component failures often result in system failure which can lead to delays of the timetabled train service. Therefore, it is important that inspection and maintenance of the OLE is carried out as necessary in order to uphold system reliability. Network Rail (NR) (the British railway infrastructure provider) aim to maintain their current assets and correctly specify the assets to be installed during system upgrades, so that the required outputs, such as system reliability and railway line speed, can be achieved at the lowest whole lifecycle cost of the system [1]. In this context, the whole lifecycle cost of an asset is composed of its acquisition costs, associated with its design and installation, and its ownership costs, associated with its failure and maintenance over the lifetime of the asset [2].

The OLE is a sub-system of the $25 \mathrm{kV}$ AC overhead electrification system, which is NR preferred electrification system, representing $63 \%$ of the electrified network and containing over $5000 \mathrm{~km}$ of railway. With such a large electrified network and new electrification installations planned in the near future, substantial economic savings can be realised through specifying the OLE installation types and maintenance regimes that achieve the required outputs at the lowest whole lifecycle cost. Through modelling OLE component degradation and failure over the lifecycle of the system, whilst also taking into account the inspection and maintenance regimes, the expected whole lifecycle cost for a given OLE installation type and maintenance regime can be estimated. The results for different project options and maintenance regimes can then be compared, and future asset management and investment decisions can be better informed. 
Relatively little research into asset management and lifecycle cost modelling of the OLE has been considered to date. The main modelling approaches, described in literature and used in railway industry, encompass deterministic methods, such as finite element analysis and dynamic lumped mass modelling of the OLE, which are used to investigate component behaviour and the interaction between train pantographs and the OLE system [3]. Such methods are useful when considering the design specifications for a new electrified line, such as the tension in the catenary and contact wires and the span length. Some reliability-based techniques have also been applied in this field, for example, [4] performed the survival analysis of the OLE components on the French railway network and found that the Weibull distribution can be used to represent OLE component lifetimes. Similarly, the FMEA method was applied on the Spanish railway network in order to identify the criticality of the OLE components [5], or the overall reliability of the OLE system and its critical components was also identified using FTA [6]. Such analyses have then been used to determine and optimise inspection intervals of the OLE components [7]. In addition, simulation has been applied in order to estimate component reliability and maintenance costs, for example, Ho et al. described this process for a railway traction power system, taking into account fixed-time preventative maintenance and corrective maintenance after a failure [8]. Similarly, Min et al. considered a number of maintenance actions (such as repair, replace or do nothing) with their costs and reliability improvements [9]. In addition, a genetic algorithm method was used to find optimum maintenance strategies by minimising the cost and maximising system reliability.

The stochastic models, described above, could be used to estimate the whole lifecycle cost of the OLE components and support the decision making in asset management, although with some limitations. A more detailed approach is required to take into account the dependencies between the OLE components and the maintenance and inspection processes undertaken by NR, as part of their asset management strategy. For example, instead of a fixed-time preventative maintenance approach, NR implement a condition-based maintenance regime, where maintenance is scheduled based on the condition of the components, which is revealed during routine inspections. In addition, in order to reduce the number of maintenance visits and the disruption to the railway service due to maintenance, opportunistic maintenance is often performed. These maintenance regimes are becoming more common in industry, for example, [10] provided an overview of condition-based maintenance and its advantages, and [11] described the main features of opportunistic maintenance and its application in industry.

This paper describes a High Level Petri Net (HLPN) model that has been developed to simulate the degradation, failure, inspection and maintenance of the OLE components. Petri Nets (PN) are used to represent the behaviour of a system by modelling the concurrent or asynchronous events that occur, and Carl Petri first developed PNs in 1962 [12]. Like Markov models, PNs are often used to graphically represent a state-based model, where different states (known as places) refer to different conditions of the system modelled. However, unlike Markov models, the transitions between places in PNs are not limited to occur at a constant rate. Due to their power and flexibility, PNs have been used in a variety of different fields, such as modelling system reliability and behaviour in engineering systems [13] [14]. Similarly, PNs have been developed to model the process of asset management. For example, [15] described a PN that modelled the degradation and maintenance of a section of railway track. HLPNs, which are used in this paper, add further functionality to standard PNs, and they can model complex processes in a more efficient and intuitive manner. This is enabled using tokens containing additional information that can be manipulated by functions within the transitions and their arcs. Jensen and Kristensen in [16] explained the concept and methodology of Coloured Petri nets, which are an example of HLPNs. For example, [17] showed the advantages of Coloured Petri nets for modelling degrading and repairable systems with tokens that contain additional information, such as component age, that is not limited to changing discretely upon the firing of a transition. This paper 
follows the framework stipulated within HLPN standards [18], which encompasses the features used in Coloured Petri nets, but uses different terminology.

A novel OLE system model is proposed in this paper, where a large number of component instances in a system can be modelled simultaneously using a single general model, and the dependencies between components, such as their grouping for opportunistic inspection and maintenance, can be modelled in an efficient way. In addition, condition-based maintenance of the OLE is also included, to replace the fixed-time preventative maintenance approaches. The paper describes the development of an HLPN and its usage for evaluate the lifecycle cost, future maintenance requirements and reliability of the system, which can support OLE asset management decisions.

First of all, the paper describes the OLE system and the various asset management features that are considered (section 2). An overview of the HLPN is given next, followed by the details of the HLPN for the OLE components, using an example of the catenary wire, and the overall system (section 3 ). A description of the application of the model to a two-mile line and example results are given (section 4 ), followed by the conclusions of the paper (section 5).

\section{OLE System Description and Maintenance}

Live conducting wires, insulators and supporting equipment installed along the line are collectively referred to as the OLE. The main OLE components, shown in Figure 1, repeat down the entire length of an electrified line and are supported by structures. The registration equipment is attached to the structures via insulators that separate the live components from Earth. The contact and catenary wires are attached to the registration equipment with the contact wire suspended below the catenary wire using dropper wires, such that the height above the track is the same along the line. The train pantograph rubs against the contact wire, which carries the current, to obtain traction power. Above the plain line track, the contact and catenary wires are approximately 1 mile long. This length, and the OLE components located within it, is referred to as a wire run. The contact and catenary wires overlap between two wire runs. A wire span, and the OLE components located within it, is between two adjacent structures, and it is commonly between 50 to 70 metres long, note that 60 metres spans on a plain line are considered in this study.

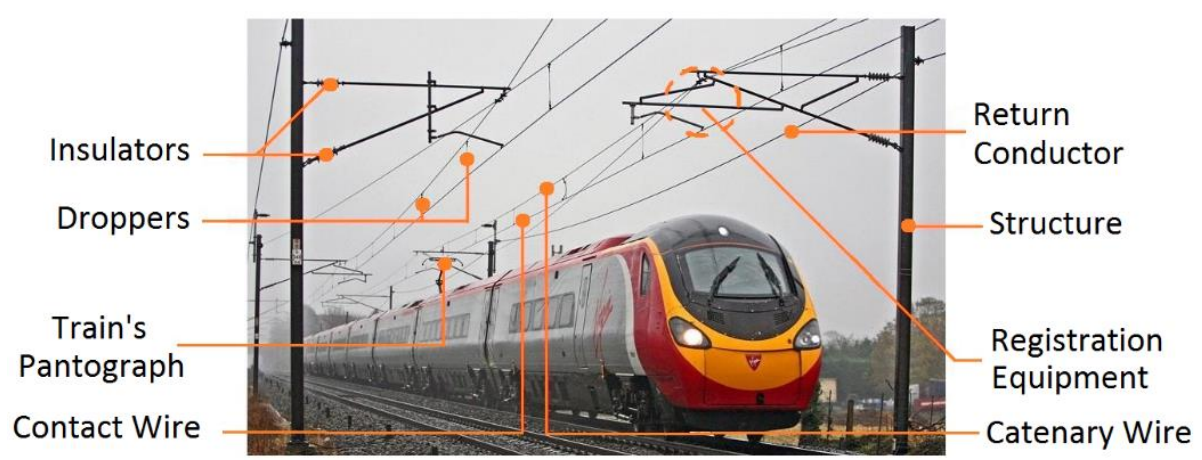

Figure 1. OLE Components

NR apply condition-based maintenance to the OLE, whereby maintenance of an individual component is scheduled based on the condition that it was found to be in during routine inspections. They have guidelines that describe the maximum time that maintenance for each component level of degradation must be completed by, in order to reduce the risk of the OLE system failure (NR, 2011). However, since maintenance engineers are responsible for many OLE components, and obtaining access to and isolating the line is often logistically constrained, the components requiring maintenance 
in the same area are scheduled to be maintained opportunistically at the same time. The size of such an area is dependent on the access to the line. In this paper it is assumed that maintenance of components in 2 wire runs, i.e. an area of 2 miles long, can be undertaken during the same visit, which is referred to as an access area.

Routine inspections are carried out in order to assess the condition of the OLE components. The main inspection regimes include: a low level walking inspection (where the components are inspected at the ground level), a cab patrol (where maintenance engineers inspect the components from a train driving at slow speed, hence not all defects can be revealed during this inspection), and a high level intrusive inspection (where the line is isolated and the components are inspected at high level, and maintenance will be undertaken at the same time while the line access is granted). Service affecting component failures are revealed sooner than the frequency of the routine inspections, by the power supply tripping or by alerts from rail users, such as train drivers. Such failures result in delays to the timetabled train service, and substantial costs, due to the ensuing delays, are incurred by NR. It is therefore imperative that regular inspections are undertaken to identify degraded components, so that their maintenance is scheduled to reduce the occurrence of service affecting failures.

The inspection regimes reveal defect of components that maintenance must address in order to prevent failures. The maintenance actions that rectify the defects depend on the component type. For instance, in the case of an insulator a like-for-like replacement is carried out. For contact wire, the degraded section of the wire is taken out and replaced by a new wire splice. For registration equipment, adjustment and retightening is performed. In addition to maintenance, large scale renewals can also be carried out, where a large number of components is renewed, such as the entire contact wire and catenary wire in a wire run of the OLE. Renewals are usually scheduled to occur when the components are at the end of their service life, such 70 years for the contact wire used in this study. Maintenance of other components can also be undertaken during the renewals.

\section{Petri Net Model for OLE}

In this paper a stochastically timed HLPN, where a simple example is shown in Figure 2, has been developed for modelling the degradation, failure, maintenance and inspection processes of all of the main OLE component types that are shown in Figure 1. HLPNs work in a similar manner to standard PNs, i.e. tokens are passed between places connected via arcs when relevant transitions are enabled, for example, an asset condition changing from the working to the failed state. In addition, tokens in HLPNs can contain specific data, such as the location and maintenance history of the asset, and the transitions can process a function passed with tokens, such as calculating the asset failure cost. In comparison to the standard PN approach, these additional features make the overall model more concise and efficient, and enable HLPNs to model complex processes. The proposed HLPN model is detailed in the sections below.

\subsection{High Level Petri Nets}

\subsubsection{Basic Constituents}

As introduced above, a distinct feature of HLPNs is that the tokens can contain additional information in the form of data values. Each data value has a specified property and can belong to a set of values, e.g. a data value could be an integer in the set of $\{0,1,2,3,4,5\}$. The tokens can contain more than one data value, where the Cartesian product of the data values describes the set of data values. Each place has a specified type, which refers to the set of data values that each token must contain in order to reside in that place. In this paper, different tokens can be distinguished according to their data values, which represent different instances of each component type in the OLE system. 
The directed arcs between places and transitions show the direction of movement of the tokens. The arc expressions, listed adjacent to each arc, contain variables that refer to the data values in each token. The variables within the arcs can bind to the corresponding data value within a token in its connected place (if such a token exists). If all the variables in the arc expression can bind to the specified data values of the token, then the transition is enabled in one particular mode. The presence of a number of modes, that the transition can be enabled in, allows the different tokens in the same place to be moved concurrently, such that the transition operates independently, and a large number of components can be modelled within the same Petri net, as shown in this paper.

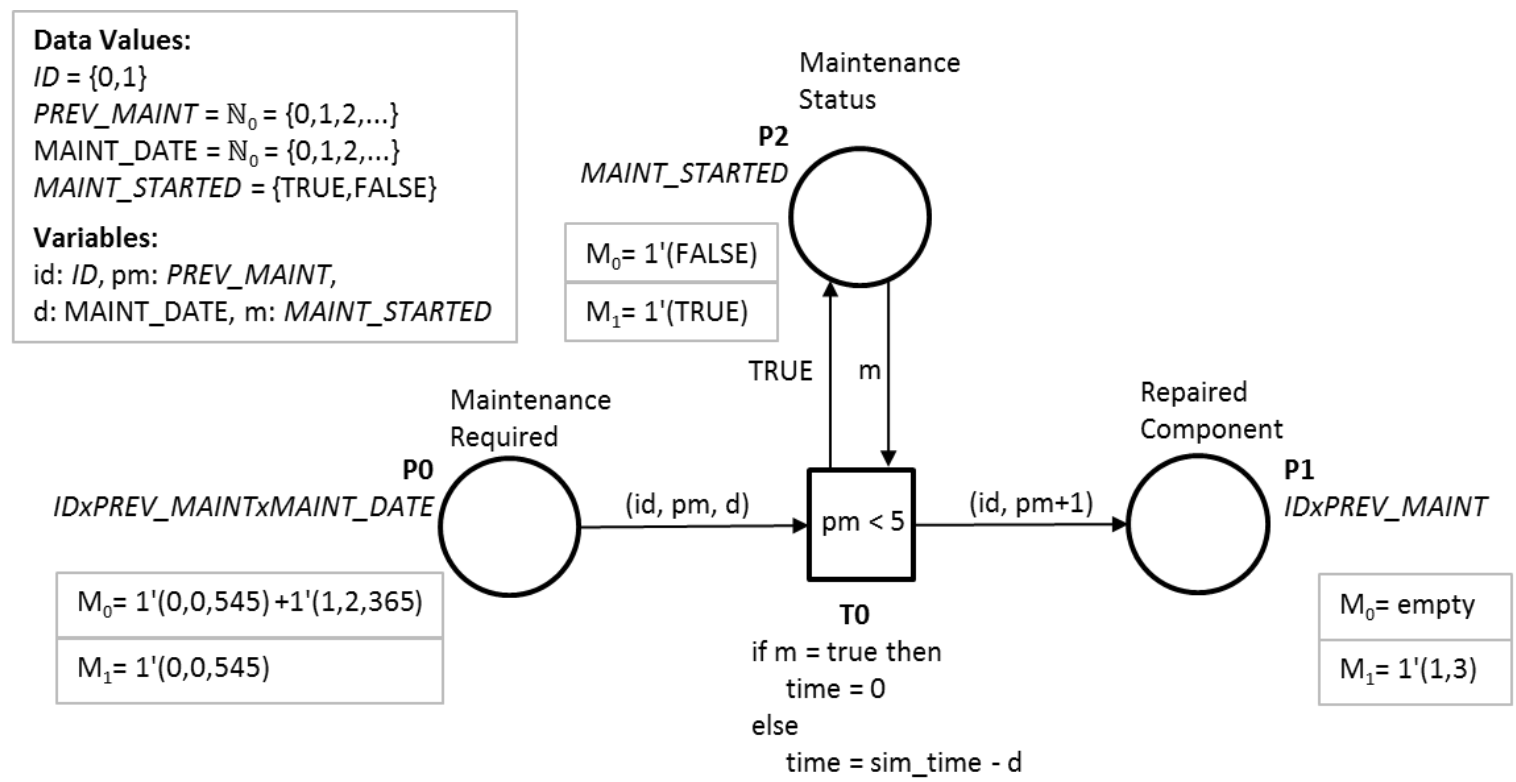

Figure 2. High Level Petri Net Example

Figure 2 shows an example of the HLPN that models a simple maintenance process for 2 components. There are 4 types of data values considered, which are described in the top left corner: 3 are integer values, referred to as ID (component ID), PREV_MAINT (the number of previous maintenance works undertaken on the component) and MAINT_DATE (the date of next maintenance in days), and 1 Boolean value, referred to as MAINT_STARTED (TRUE if maintenance is underway). There are 3 places in the model. Place PO has a type of ID x PREV_MAINT $x$ MAINT_DATE, i.e. the tokens residing in it contain three data values that are integers, and it represents the situation when the component is in the condition that requires maintenance. Place P1 models the component in the repaired condition, and it has a type of ID $\times$ PREV_MAINT. Finally, place P2 models the situation when the maintenance is underway. The initial markings of the places are listed in the boxes next to each place, denoted by expression $M_{0}$, and the updated markings, i.e. after the transition fires, are denoted by $M_{1}$. For example, Place P0 has the initial marking $M_{0}=1^{\prime}(0,0,545)+1^{\prime}(1,2,365)$. This expression means that the place contains a token with the ID value of 0 , the PREV_MAINT value equals to 0 and the MAINT_DATE value equals to 545, and another token with the ID value of 1 , the PREV_MAINT value equals to 2 and the MAINT_DATE value equals to 365 . This means, that there are 2 components (with the ID 0 and 1 respectively) in the condition that requires maintenance; the first component has not been maintained previously, and its maintenance start time is 545 days, and the second component has been maintained twice previously, and its maintenance start time is 365 days. The second component is maintained first due to its earlier maintenance start time, and the updated marking, $M_{1}=1^{\prime}(0,0,545)$, contains the first component only, as it is still to be maintained at a later date. 
The variables used in the arc expression for transition T0, such as id, pm, $d$ and $m$, bind to the corresponding data values of the tokens in the places that the arcs are connected to, i.e. P0, P1 and P2. Transition TO is enabled in two separate modes: in the first mode with id=0, $p m=0, d=545$ and $m=F A L S E$, and in the second mode with id=1, $p m=2, d=365$ and $m=F A L S E$. Therefore, a different token is absorbed from Place PO in the two different modes, in order to model two components in the same model. The transition condition $(\mathrm{pm}<5)$ placed inside the square means that the transition can only be enabled if the number of previous maintenance works, pm, is less than 5 , i.e. maintenance can only be carried out 4 times, after which a replacement (not illustrated in Figure 2 ) must be scheduled. The firing time of T0 is determined by the expression below the square. If maintenance has already started ( $m=T R U E$ ), the transition fires straightway, otherwise, it is delayed until the date of next maintenance. After the transition the marking of $\mathrm{P} 1$ and $\mathrm{P} 2$ is updated, where the number of previous maintenance works for the second component is increased, $M_{1}=1^{\prime}(1,3)$, and the maintenance is underway, $M_{1}=1^{\prime}(T R U E)$, respectively. During the next step, TO fires immediately, i.e. once maintenance has started, other components that require maintenance, such as the first component, will also be maintained at the same time. In this case, opportunistic maintenance policies can be modelled.

\subsubsection{Transition Firing Times}

Since the HLPN, developed in this paper, is a stochastically timed Petri net, Monte Carlo simulations are carried out in order to obtain model results. Transition firing times are sampled from probability distributions, such as the Weibull distribution, mostly used to model component degradation and failure processes. The distributions and their parameters have been estimated through reference to the degradation behaviour and lifetimes described in literature [19], NR data analysis and discussions with NR maintenance engineers. Some transition times are fixed, such as the time to complete the inspection and maintenance, and based on the duration taken from NR maintenance standards. An illustration of the parameter values obtained for the catenary wire is given in Table 4 in Section 3.5.

In addition, the transition firing times can also be based on the information that the tokens contain in their data values. For example, the firing time can be calculated based on a function that uses data values as parameters, as illustrated in Figure 2. Another important feature is that each mode of transition can have a different distribution assigned to it, therefore, different instances of each component type and subtype can be considered concurrently, such as porcelain or polymeric insulators, where their degradation and failure rates may vary.

\subsubsection{Reset Arcs}

Reset arcs are used to reset the marking of the tokens to zero, regardless of the initial marking of the place. They are particularly useful when modelling maintenance processes, for example, where once the maintenance is underway, the tokens describing levels of degradation before inspection need to be removed. Reset arcs are a good alternative to creating multiple transitions with various inhibitor arcs, used for identifying places that need to be cleared of tokens. As a result, reset arcs make the model more concise and computationally efficient. Reset arcs are not defined in the HLPN standards, but they are introduced in literature [20] [21].

Figure 3 shows two processes: the first process on the top of the figure models the renewal of components in a wire run, where the data value WRUN refers to the wire run, and the second process on the bottom of the figure models component degradation. Initially, there are two components in the degraded condition (place P2), the first component (id=0) is in the wire run 1 and the other component (id=2) is in the wire run 2, i.e. $M_{0}=1^{\prime}(0,0)+1^{\prime}(2,1)$, and $T 1$ is enabled in these two modes. Another component ( $i d=1$ ) that is also in the wire run 1 is in the severely degraded condition (place $\mathrm{P} 3$ ). In addition, the token representing the wire run $1(w=0)$ is waiting for a renewal to take place (in 
place PO), and T0 is enabled in this mode. If T0 fires first, in the mode $w=0$, then the token is absorbed from $\mathrm{PO}$ and fired to $\mathrm{P} 1$. The reset arcs then remove all the tokens with $\mathrm{w}=0$ in $\mathrm{P} 2$ and $\mathrm{P} 3$. Note that in this paper, the places and tokens to be reset are listed in the text below the relevant transition, TO in Figure 3. This representation is proposed due to the fact that the HLPN of the OLE can contain many reset arcs that interlink numerous places, and their pictorial representation can become too difficult to follow.

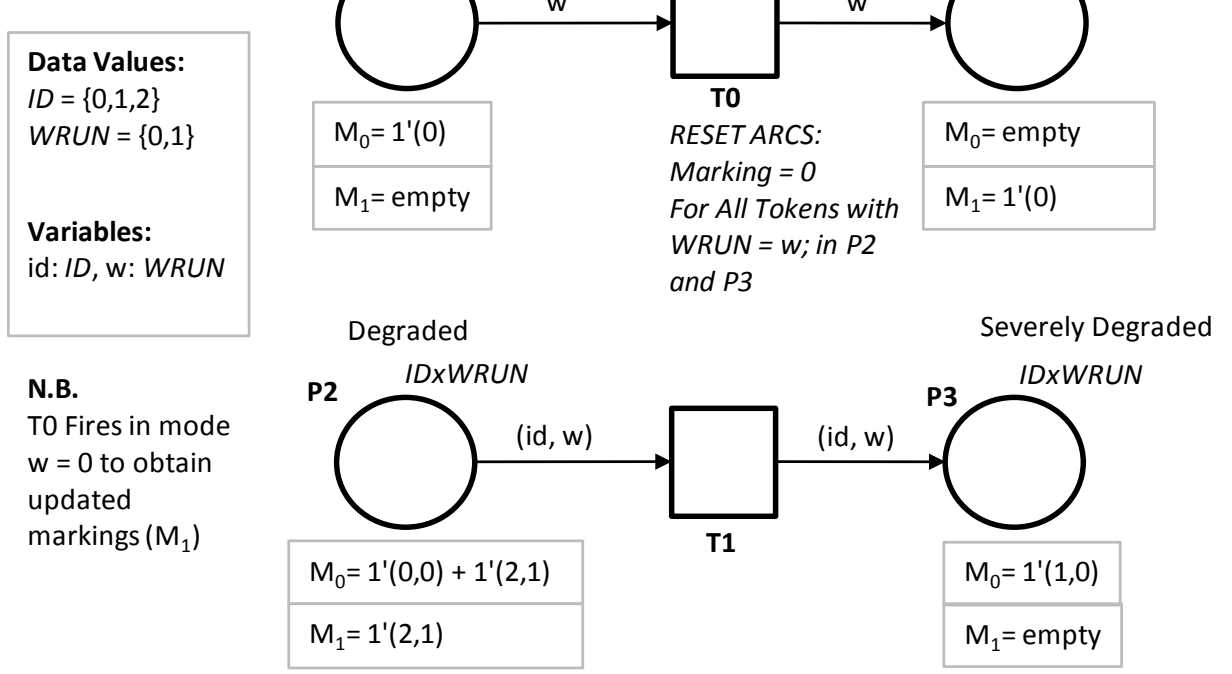

Figure 3. An Example HLPN with Reset Arcs

\subsection{OLE Components and Processes Modelled}

The following components of the OLE between two structures are considered in this paper: catenary wire, contact wire, a span of droppers, insulators ( 2 per structure), registration equipment, return conductor wire and structures, as shown previously in Figure 1. The degradation, failure, inspection and maintenance processes are modelled for each of these components. Note that only degradation and maintenance of the structures (not the failure) is considered, because data analysis has shown that service affecting failures of structures are extremely rare. Also, it is assumed that other components, such as tensioning equipment and earthing and bonding, do not influence the whole lifecycle cost significantly and, therefore, they are not modelled in detail.

Different asset management strategies, in terms of start time, duration and nature of the inspection, maintenance and renewal works, are considered and the analysis of the results is carried out in order to evaluate the suitability of different asset management strategies. Large-scale renewals, or improvement works, that involve the renewal or maintenance of a large number of components (of the same or different types) are also modelled in this paper, such as of catenary and contact wire.

In addition, random failures that result in service disruption, and are caused by some external influences but do not damage any components, are also modelled in a separate process for each wire run of the OLE studied. The analysis of NR database of failure events between 2009 and 2015 was undertaken and it showed that such external influences are described as vegetation coming into contact with the OLE, random tripping of the system due to bird strikes, or where no fault was found or incorrect reporting of component failure has occurred. 


\subsection{Approach of Model Building}

The HLPN contains a subnet for each OLE component type studied, considering their degradation, failure, inspection and maintenance. The places denote different states of component condition and they contain tokens that represent the different instances of the component type in the access area of the OLE studied. In addition, in the case of the contact and catenary wires, since they are long components (approximately 1 mile long) and their defects can occur locally, in the model they are divided into smaller sections, in order to have a unit of length that could be addressed by maintenance in practice. For example, for the catenary wire, each complete length is divided into spans between two structures, and each of these wire spans is assigned a unique token and modelled individually. Similarly, each wire run of the contact wire is split into 5 sections across its length. Therefore, each component is associated with its wire run and span, used for identifying the location, necessary for implementing opportunistic maintenance and inspection. Note that each individual subnet for a component type can be analysed separately (without considering other types at the same time) if required.

In the whole system HLPN the individual subnets and their tokens are interlinked through modelling the processes of inspection and maintenance. For example, during opportunistic maintenance the components that are known to require maintenance in a specific access area can be maintained earlier, i.e. at the same time as other components with more urgent maintenance needs. Similarly, during opportunistic inspections, when maintenance is being undertaken on one component other component types in the same access area are also inspected. Additionally, if a failure occurs, a lowlevel inspection of all the components located in the wire run of the OLE with that failure is undertaken. During renewals, other component types may also be maintained or renewed, for example, the catenary wire and contact wire can be renewed together. The way that these different interactions are modelled is explained in section 3.6, which describes the whole system model in detail.

\subsection{Representation of the OLE Components and System}

In the proposed HLPN model, the tokens are used to represent the individual OLE components, their wire spans, runs and the access area that the components exist in. In order to capture this information in the model the following data values are introduced, as listed in Table 1.

Table 1. HLPN Data Values

\begin{tabular}{|l|l|l|l|}
\hline Data Value & Description & Type & Property \\
\hline ID & Component ID & integer & $\begin{array}{l}\{0,1, \ldots, \text { number of } \\
\text { instances of component } \\
\text { type-1 }\}\end{array}$ \\
\hline SPAN & $\begin{array}{l}\text { The span of OLE the component is } \\
\text { located in }\end{array}$ & integer & $\begin{array}{l}\{0,1, \ldots, \text { number of spans- } \\
1\}\end{array}$ \\
\hline WRUN & $\begin{array}{l}\text { The wire run of OLE the } \\
\text { component is located in }\end{array}$ & integer & $\begin{array}{l}\{0,1, \ldots, \text { number of wire } \\
\text { runs-1 }\end{array}$ \\
\hline AREA & $\begin{array}{l}\text { The access area the component is } \\
\text { located in }\end{array}$ & integer & $\begin{array}{l}\{0,1, \ldots . \text { number of areas - } \\
1\}\end{array}$ \\
\hline INST_DATE & $\begin{array}{l}\text { The installation date of the } \\
\text { component }\end{array}$ & integer & $\begin{array}{l}\text { Relative to the start of the } \\
\text { simulation }\end{array}$ \\
\hline LAST_MAINT_DATE & $\begin{array}{l}\text { The date that maintenance was } \\
\text { last undertaken on the component }\end{array}$ & integer & $\begin{array}{l}\text { Relative to the start of the } \\
\text { simulation }\end{array}$ \\
\hline PREV_MAINT & $\begin{array}{l}\text { The number of previous } \\
\text { maintenance actions undertaken } \\
\text { on the component }\end{array}$ & integer & $\begin{array}{l}\mathbb{N}_{0} \text { (Positive Integers } \\
\text { including 0) }\end{array}$ \\
\hline
\end{tabular}




\begin{tabular}{|l|l|l|l|}
\hline MAINT_DATE & $\begin{array}{l}\text { The date maintenance of the } \\
\text { component must be completed by }\end{array}$ & integer & $\begin{array}{l}\text { Relative to the start of the } \\
\text { simulation }\end{array}$ \\
\hline MAINT_STARTED & $\begin{array}{l}\text { Maintenance is currently } \\
\text { underway }\end{array}$ & Boolean & $\begin{array}{l}\text { TRUE if maintenance has } \\
\text { started, otherwise FALSE }\end{array}$ \\
\hline TIME_REMAINING & $\begin{array}{l}\text { Number of time units remaining in } \\
\text { a maintenance visit }\end{array}$ & integer & $\begin{array}{l}\{0,1, \ldots, \text { number of time } \\
\text { units in a visit }\}\end{array}$ \\
\hline COST & $\begin{array}{l}\text { The cost associated with } \\
\text { component failure or maintenance }\end{array}$ & integer & $\mathbb{N}$ \\
\hline
\end{tabular}

For example, Figure 4 shows an illustration of how some data values for an insulator are used. Note that there are two insulators on each structure. For example, the ID data value is used to distinguish between the different instances of the insulators in the area studied. Similarly, each insulator is also assigned a SPAN, WRUN and AREA data values, which refers to the wire span, the wire run and the access area that the insulator is located in, respectively.

In addition, for the places that model component failures, the tokens also contain a COST data value that describes the cost incurred due to failure. Further illustration of the use of data values is given in the following section with the example of the catenary wire HLPN.

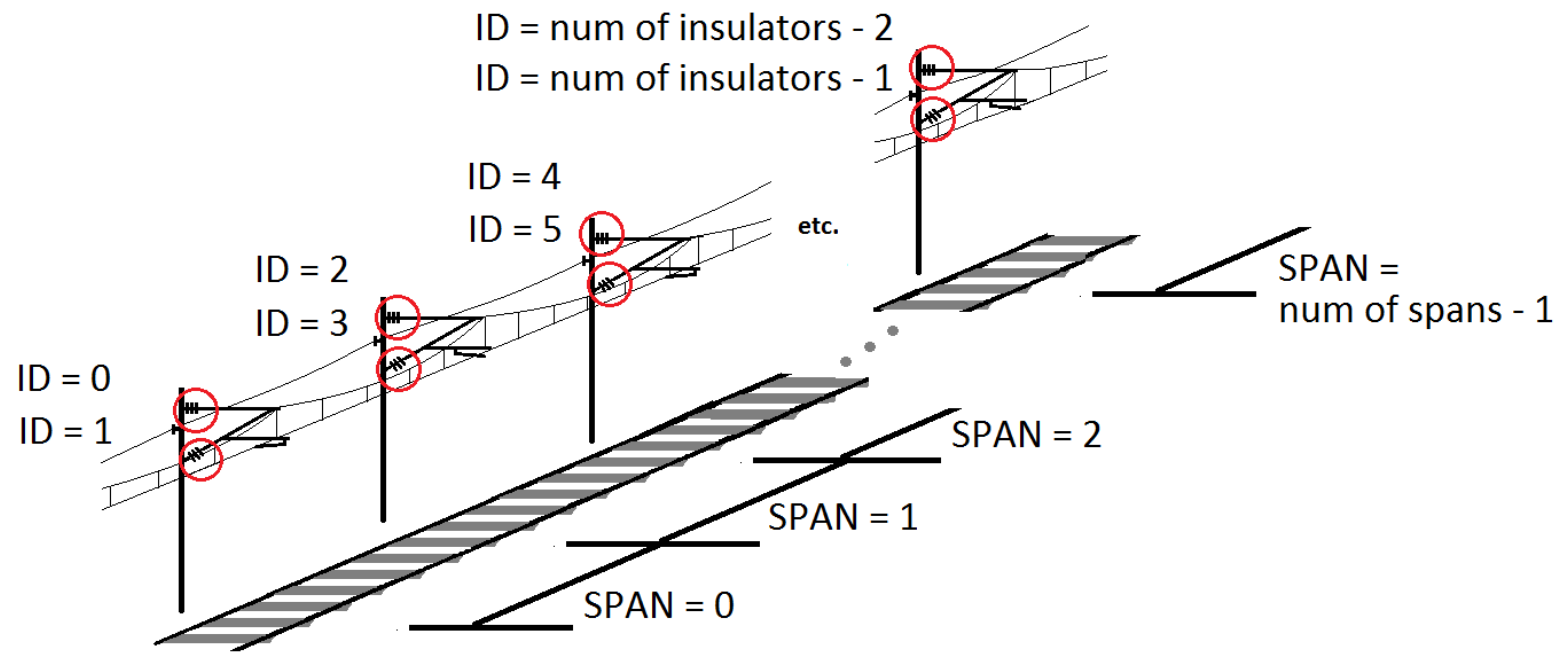

Figure 4. ID and SPAN Data Values for Tokens Representing an Insulator

\subsection{Example of Catenary Wire HLPN}

Figure 5 shows a subnet that represents the degradation, failure, inspection and maintenance processes of the catenary wire. Table 2 lists the variables used in the arc expressions, Table 3 lists all the places and Table 4 lists all the transitions. The different processes modelled in this subnet are explained, with reference to Figure 5, as follows.

Table 2. Variables Used in the Arc Expressions in Figure 5

\begin{tabular}{|c|c|}
\hline Variables & Data Value It Binds to \\
\hline id & ID \\
\hline s & SPAN \\
\hline w & WRUN \\
\hline a & AREA \\
\hline in & INST_DATE \\
\hline Im & LAST_MAINT_DATE \\
\hline pm & PREV_MAINT \\
\hline
\end{tabular}




\begin{tabular}{|c|c|}
\hline $\mathrm{md}$ & MAINT_DATE \\
\hline $\mathrm{tr}$ & TIME_REMAINING \\
\hline $\mathrm{m}$ & MAINT_STARTED \\
\hline $\mathrm{CW}=$ set of variables: $(\mathrm{id}, \mathrm{s}, \mathrm{w}, \mathrm{a}$, in, $\mathrm{Im}, \mathrm{pm})$ \\
\hline sim_time = the current simulation time
\end{tabular}

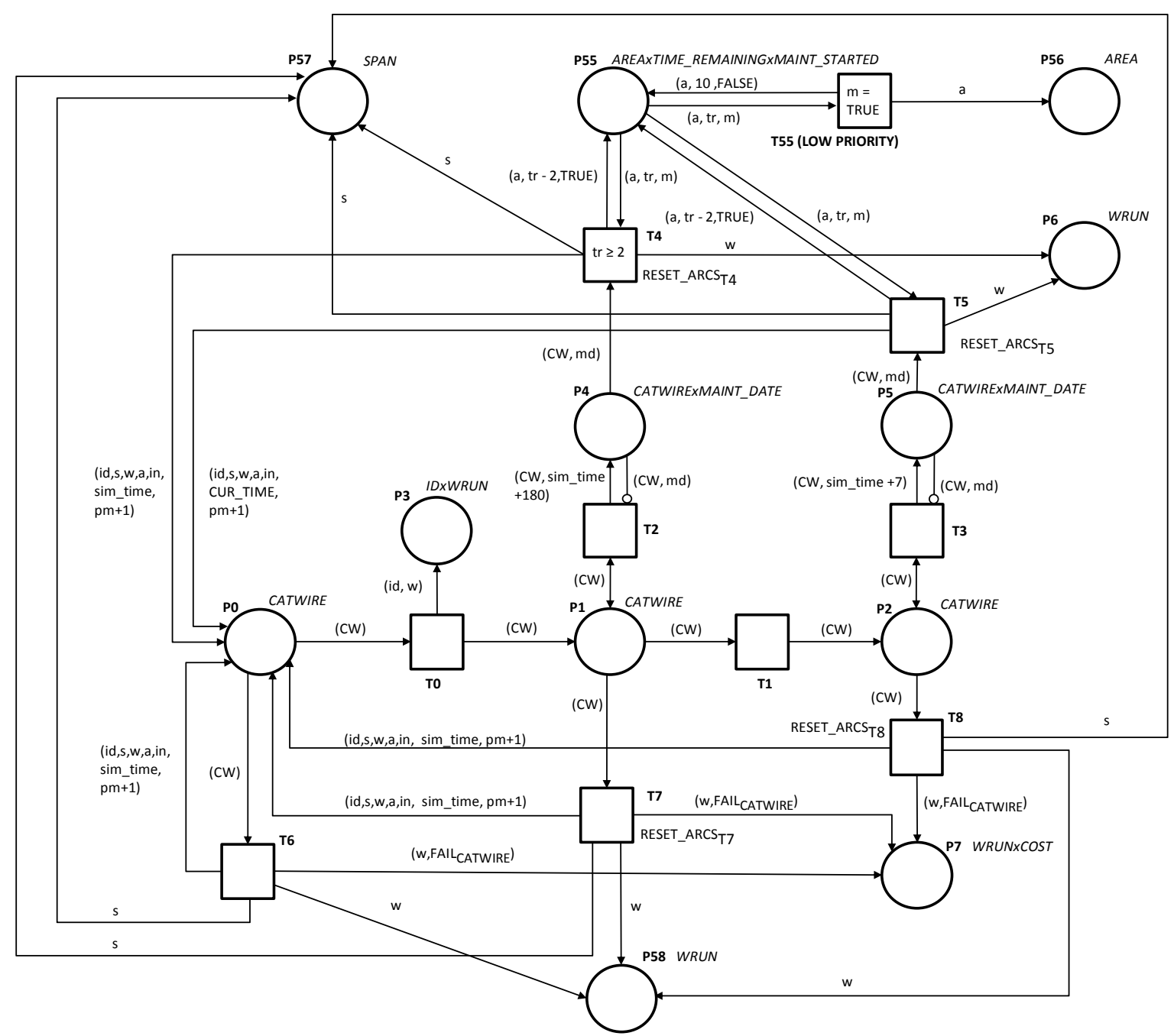

Figure 5. Example Subnet for the Catenary Wire

Table 3. Description of Places in Figure 5

\begin{tabular}{|l|l|l|}
\hline Place & Description & Type \\
\hline P0 & Good / Working Condition & CATWIRE* \\
\hline P1 & $\begin{array}{l}\text { Degraded Condition (section of catenary wire has a single } \\
\text { strand of wire burst or minor damage) }\end{array}$ & CATWIRE* \\
\hline P2 & $\begin{array}{l}\text { Severely Degraded Condition (section of catenary wire has } \\
\text { multiple strands of wire burst or extensive damage) }\end{array}$ & CATWIRE* \\
\hline P3 & $\begin{array}{l}\text { Records statistics associated with the number of degraded } \\
\text { sections of catenary wire for a certain wire run }\end{array}$ & ID x WRUN \\
\hline P4 & $\begin{array}{l}\text { Revealed Degraded Condition (the maintenance engineers } \\
\text { are aware of the degradation and maintenance is } \\
\text { scheduled) }\end{array}$ & $\begin{array}{l}\text { CATWIRE* } x \\
\text { MAINT_DATE }\end{array}$ \\
\hline
\end{tabular}




\begin{tabular}{|c|c|c|}
\hline P5 & $\begin{array}{l}\text { Revealed Severely Degraded Condition (the maintenance } \\
\text { engineers are aware of the degradation and maintenance is } \\
\text { scheduled) }\end{array}$ & $\begin{array}{l}\text { CATWIRE* }{ }^{*} \\
\text { MAINT_DATE }\end{array}$ \\
\hline P6 & $\begin{array}{l}\text { Records statistics associated with the number of } \\
\text { maintenance works undertaken on the wire run of catenary } \\
\text { wire }\end{array}$ & WRUN \\
\hline P7 & $\begin{array}{l}\text { Records statistics associated with the number of service } \\
\text { affecting failures of the catenary wire and the } \\
\text { corresponding costs incurred }\end{array}$ & WRUN $\times$ COST \\
\hline P55 (global) & Describes the current maintenance status of the access area & $\begin{array}{l}\text { AREA } x \\
\text { TIME_REMAINING } x \\
\text { MAINT_STARTED }\end{array}$ \\
\hline P56 (global) & $\begin{array}{l}\text { Records statistics associated with the total number of } \\
\text { maintenance visits to an access area }\end{array}$ & AREA \\
\hline P57 (global) & $\begin{array}{l}\text { The span of OLE is currently undergoing maintenance. This } \\
\text { is an enabling place for transitions that represent } \\
\text { opportunistic high level inspection of components located } \\
\text { in this span. }\end{array}$ & SPAN \\
\hline P58 (global) & $\begin{array}{l}\text { The wire run of OLE contains a failed component. This is an } \\
\text { enabling place for transitions that represent opportunistic } \\
\text { low level inspection of components located in this wire run. }\end{array}$ & WRUN \\
\hline
\end{tabular}

Table 4. Description of Transitions in Figure 5

\begin{tabular}{|c|c|c|}
\hline Transition & $\begin{array}{l}\text { Function/ } \\
\text { Feature }\end{array}$ & Information (time in days) \\
\hline T0 & Firing time & $\begin{array}{l}\text { If } \mathrm{pm}=0 \text { then } \\
\text { Sampled from Weibull distribution: } \beta=2.5, \eta=43800 \\
\text { Else } \\
\quad \text { Sampled from Weibull distribution: } \beta=1.5, \eta=36500\end{array}$ \\
\hline T1 & Firing Time & Sampled from Weibull distribution: $\beta=3, \eta=1825$ \\
\hline T2 and T3 & Firing Time & $=$ sim_time - date of next low level inspection (every 28 days) \\
\hline T4 and T5 & Firing Time & $\begin{array}{l}\text { If } m=\text { 'TRUE' then } \\
\quad \text { Fire Time }=0 \\
\text { Else } \\
\quad \text { Fire Time }=m d-\text { sim_time }\end{array}$ \\
\hline T4 & RESET_ARCS ${ }_{\text {T4 }}$ & Marking $=0$ for all tokens with ID = id in: P1, P2, P3 and P5 \\
\hline T5 & RESET_ARCS ${ }_{T 5}$ & Marking $=0$ for all tokens with ID $=$ id in: $\mathrm{P} 2, \mathrm{P} 3$ and $\mathrm{P} 4$ \\
\hline $\begin{array}{l}\text { T6, T7 and } \\
\text { T8 }\end{array}$ & FAIL & $\begin{array}{l}=\exp (\mu+\sigma Z) \\
\text { Samples from lognormal distribution } \\
\mu \text { and } \sigma \text { are location and scale parameters respectively, which are } \\
\text { hidden on request by NR } \\
Z \text { is a standard normal random number }\end{array}$ \\
\hline T6 & Firing Time & Sampled from exponential distribution: $\lambda=4.6 \cdot 10^{-7}$ \\
\hline $\mathrm{T7}$ & Firing Time & Sampled from exponential distribution: $\lambda=2.7 \cdot 10^{-4}$ \\
\hline $\mathrm{T7}$ & RESET_ARCS ${ }_{T 7}$ & Marking $=0$ for all tokens with ID $=$ id in: P3 and P4 \\
\hline T8 & Firing Time & Sampled from Weibull distribution: $\beta=3, \eta=500$ \\
\hline T8 & RESET_ARCS & Marking $=0$ for all tokens with ID $=$ id in: $\mathrm{P} 3$ and P5 \\
\hline T55 & Firing Time & $=0$ \\
\hline
\end{tabular}




\subsubsection{Component Degradation and Inspection}

A subnet for each OLE component type contains places that represent the condition of the component, such as the working condition and the degraded condition. Some OLE components may have multiple degradation mechanisms, for example, the catenary wire can degrade due to corrosion, as well as fatigue. However, rectifying the degradation will require the same maintenance action, and in this paper it is also assumed that one degradation mechanism will dominate over others, or the number of different degradation mechanisms can be grouped together and modelled by one process. In practice often there is no quantifiable parameter that determines the exact condition of the OLE component. Since the degraded condition refers to the extent of maintenance, the rate of degradation can, therefore, be based on maintenance records, by considering the time it takes for a component to degrade to a level when maintenance is scheduled. As discussed in section 3.1.2, using this approach the probability distributions are derived to describe the transitions in the degradation model.

The degradation states themselves are defined according to the NR maintenance policies, where the maximum time that maintenance must be completed by, for different severities of degradation or component defects, is specified. For each OLE component type there is one or two states of degradation defined - a degraded state and a severely degraded state. The difference between these two states comes from the level of urgency for maintenance, where the maximum maintenance time is smaller for a component in the severely degraded state than in the degraded state. Note that some components, such as the registration equipment, do not have a severely degraded state in the model, since the maintenance standards stipulate only one maximum maintenance time. This approach of state definition has been taken due to the availability of historical records of maintenance works and component failures, which was collected based on the current policies, i.e. a more severe level of degradation needs to be addressed by maintenance works more urgently. An alternative would be to define the states using a quantifiable degradation parameter, such as the amount of wear of the contact wire. In general, it can be difficult to evaluate the condition of such OLE components accurately until a defect becomes apparent, for example, before a strand bursts on the catenary wire. If the degradation could be measured and such data was collected, the component states in the model could be defined accordingly, for example, the state could represent the amount of wear, and definition would not need to relate to maintenance works only.

In the HLPN in Figure 5, the condition of the catenary wire is described by 3 states, P0, P1 and P2, where each degraded condition is revealed during the inspection, denoted by revealed states, $\mathrm{P} 4$ and P5. Transition T0 models the degradation from the good state to the degraded state. Note that at the same time $\mathrm{P} 3$ records the statistics, associated with the degraded condition, such as the duration that the different sections of the catenary wire spend in this condition. In order to model the different degradation behaviour after a certain number of maintenance works, T0 depends on component maintenance history. This process is described in the second row of Table 4, when one set of parameters for the distribution is used for the component with no previous maintenance works, and the other set - when at least one previous maintenance work has been undertaken. For example, the maintenance action of the catenary wire involves repairing the component, commonly by wrapping up the damaged part of the section or splicing it out. Therefore, it is assumed that because of this wrapped or spliced part of the section of the catenary wire, and the fact that the other parts will have continued to age, the overall section of catenary wire will degrade differently after the first maintenance, hence two different distributions are used before and after the first maintenance. 
Transition T2 relates to low level inspections, scheduled to occur every 28 days. Once the degraded state is revealed (P4), the maintenance needs to be completed within 180 days, as illustrated in the arc expression from T2 to P4. Transition T3 works in the same way, however, in the severely degraded condition maintenance is required more urgently, i.e. within 7 days. Note that these maintenance times are set to match the times stipulated in the maintenance standards used by NR [22].

\subsubsection{Component Maintenance}

The time when maintenance is scheduled to start depends on a number factors. First of all, due to access restraints and the fact that a maintenance team is responsible for a large section of electrified line, a number of maintenance actions are usually scheduled to occur at the same time. Each maintenance visit has an associated cost, line isolation and staff costs, therefore, grouping together the maintenance of different components in the same access area can reduce the number of maintenance visits required and their costs. This is also beneficial in terms of logistics, as gaining the access to a particular area can be problematic due to other railway assets present. Secondly, maintenance engineers aim to ensure that the components are not over-maintained, therefore, not all the required maintenance actions at one time will be carried out. For instance, component defects with a low priority, such that their maintenance is not required for over another year, might not be maintained early to try to get the most out of the components' service lives. Furthermore, some maintenance actions may be lengthy and limit the maintenance works of other components, therefore, they might be postponed until the next scheduled event of maintenance works, but still within the required time of completion.

Due to these intricacies the maintenance scheduling process is quite complex, therefore, the following rules were proposed. First of all, it is assumed that maintenance is scheduled using the maximum date that it has to be completed by. However, if there are other maintenance works already scheduled to occur in the same access area but at an earlier date, then the component is scheduled to be maintained at the same time, if there is enough time available. Similarly, if maintenance is scheduled to occur at an earlier date than other maintenance works in the access area, then the other maintenance actions are brought forward to occur at the same time, if there is enough time available. The first maintenance actions to be considered for opportunistic maintenance are the ones that must be completed with more urgency.

Transitions T4 and T5 in Figure 5, model the maintenance process of the catenary wire. Upon entering P4, transition T4 becomes enabled. Note that P55, which is also another input place for T4, is a global place, i.e. it is linked to each component subnet, and it signifies whether maintenance in each access area has started. For example, a TIME_REMAINING data value indicates the amount of available time to perform maintenance during a single visit to the access area. The firing time of $\mathrm{T} 4$ is obtained using a function, described in the fifth row of Table 4, that allows the maintenance scheduling rules proposed to be implemented. If the maintenance in the access area has already began, $m=T R U E$, and there are at least two time units of maintenance left (this is how long the maintenance of the catenary wire takes), tr $>=2$, the transition fires immediately (i.e. it is opportunistically maintained at the same time as other scheduled maintenance). Otherwise, it is delayed until the maximum maintenance date, md-sim_time. This might change if other components require some maintenance before this scheduled time.

Three other output arcs are associated with T4. For example, a token containing the wire run information fires to P6, which records the statistics associated with the maintenance of the catenary wire. Also, a token with a SPAN data value fires to P57, which enables opportunistic inspection of other components in the same span to take place (which is not illustrated in Figure 5). In addition, a token 
is also fired back to P0, to model the fact that the component has been repaired to the good condition, the number of previous maintenance actions is increased by 1 , and the date when the last maintenance is completed is the current simulation time, as shown in the arc expression of the output to P0, (id, s, w, a, in, sim_time, pm+1). Transition T5 works in a similar way but it represents maintenance of a severely degraded section of catenary wire, therefore, more urgent maintenance is scheduled (within 7 days rather than 180 days).

Transitions T4 and T5 also have reset arcs, as listed in Table 4, which are used to remove the tokens representing this section of the catenary wire from other places.

\subsubsection{Component Failure}

Component failure is considered to be an event, where an interruption to the timetabled train service occurs, i.e. it is a service affecting event. In this situation a component may not have failed, but its degradation is so severe that the line has to be closed or speed restrictions put in place, in order to minimise the risk of a serious system failure. Historical failure records between 2009 and 2014 have been analysed in this study, by first of all categorising the records according to each component type. Each record contained information about the costs incurred as a result of the failure (due to delay to the service and rectification work). For each component type, a distribution of failure costs was fitted by analysing the data, and a lognormal distribution was found to be a suitable fit for all the component types, as shown in Table 4. Then transitions which represent component failures were introduced in the model, where their output arcs contain a function, which samples the cost incurred due to the failure of the component from the corresponding distribution of failure costs. The different magnitude of failure costs incurred allowed different severities of failure to be taken into account.

For example, Transition T6, described in the eighth row of Table 4, fires a token to P7, which contains a value of cost, obtained from the function FAILCATwIRE. Note that P7 records statistics about the number of failures of the catenary wire and their costs. In addition, immediate, rapid-response maintenance works take place to rectify the state of the component, and a token is fired back to PO, i.e. the condition is good. At the same time, a token containing the SPAN data value, that corresponds to the span that the component is located in, is fired to P57, which enables a high level inspection of other components in the same span. Similarly, a low level inspection of other components in the related wire run is initiated. Transitions 77 and T8 work in a similar way, and represent the section of the catenary wire failing from the degraded and severely degraded states respectively. It is assumed that when a component fails from a working condition, expressed by T6, it is due to random processes, such as manufacturing defects or damage from third parties (an object blown onto the OLE or train's pantograph causes damage), i.e. a failed state is reached without component degradation. A failure rate due to these random processes from the degraded and severly degraded conditions is very low in comparison to the increased failure rate from these states due to component degradation.

\subsection{Whole System HLPN}

In the whole system HLPN, all the individual subnets for each component type are included in the model and they contain tokens representing each instance of each component type in the area of OLE studied. Each subnet is developed in a similar manner to the subnet of the catenary wire, described in section 3.5. Figure 6 shows the diagrammatic representation of the whole system model. The subnets for each component type are shown as super transitions and denoted by double-lined squares. Some global places, P55, P56, P57 and P58, as described in Table 3, are also used to connect the different subnets. The main dependencies between the individual subnets are listed below, which are introduced for a close-to-reality representation of inspection and maintenance processes, implemented by NR: 
- As described in the maintenance section (in section 3.5.2), component maintenance can be grouped together to occur during a single maintenance visit in the access area.

- Additionally, two forms of opportunistic inspection are modelled. Firstly, when maintenance is undertaken on a certain component, during the scheduled maintenance or when rectifying a service affecting failure, an opportunistic high level inspection is carried out on other components in the same span, since maintenance engineers are in the close vicinity of these components and their condition can be assessed. Secondly, after a service affecting failure, a low level walking inspection is carried out on other components in the same wire run.

In addition, the failure of the overall system due to external factors is modelled by a super transition at the right top corner, i.e. components are not damaged, but service delays occur, mainly caused by encroaching vegetation or bird strikes leading to system short-circuiting, as described in section 2 . Note that the structures subnet (super transition 7) is not linked to the global places that enable opportunistic inspection, such as P57 and P58, because their degradation is very slow and their failures are not modelled (due to their extremely rare occurrence). During large scale renewals, such as the renewal of the contact and catenary wire, system improvements are scheduled, as illustrated by a super transition at the bottom left corner.

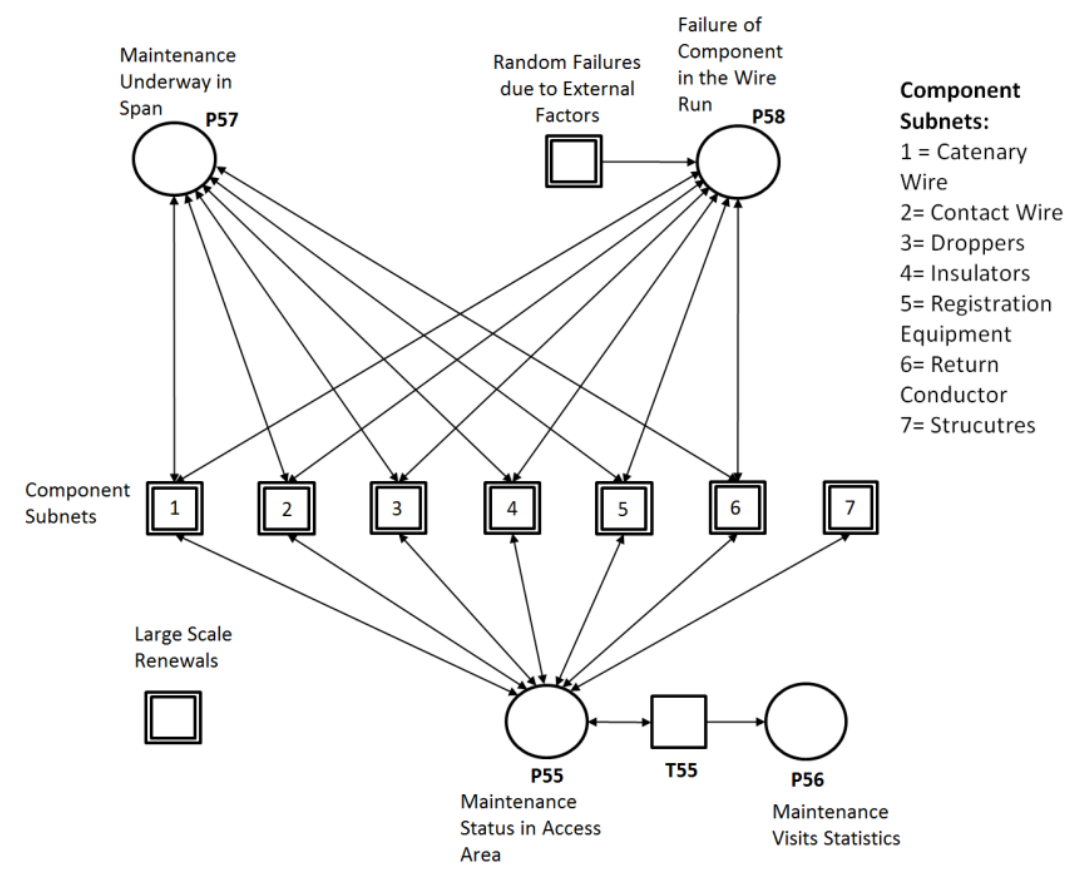

Figure 6. Whole System HLPN

\section{Application of the HLPN Model}

The main usage of the model is to calculate the expected costs, maintenance volumes and number of failures over the lifecycle of the system, as a whole and for the component types. Different asset management strategies, such as inspection and maintenance start times, can also be tested in the model, in order to understand their effects on system reliability and the expected costs. Similarly, for major projects requiring substantial capital expenditure, such as new electrification schemes or major system upgrades, the model could be used to calculate the expected whole lifecycle costs of the different options, e.g. use different OLE types or their maintenance policies. An informed decision on what option is best can be based on the statistics calculated, also taking into account the degree of uncertainty of the results. 
The model was validated by running individual component type PNs and the whole system model and by changing the values of parameters, in order to check for accuracy of transition firing times and of the process of passing tokens between places. The numerical results, such as the number of failures, maintenance works and the cost, have been checked against the values witnessed by NR, obtained from the analysis of historical data and calculated by current life cycle cost models of NR.

For an illustration of the HLPN application in this paper, the HLPN model was used to simulate 100 years of operation of all the main OLE components on a high category line, which represents high speed and high usage, in an access area of 2 miles, which contained 2 wire runs with 26 structures in each, on plain line track. All 364 components in the system were initially in a new condition. The 100 year timeframe was chosen to allow the entire lifecycle of most components to be witnessed, since most of the OLE component lifetimes are typically between 40 and 80 years [19]. As discussed previously, the inspection frequencies and maximum maintenance times for the different components were taken from NR guidelines for a high category line. A large scale renewal of the contact and catenary wires was assumed to take place after 70 years, in order to represent the end of the service life. To provide a comparison, the model was also used to evaluate the performance of the system, without undergoing opportunistic maintenance.

The HLPN developed contained 65 places, 70 transitions and 380 unique tokens. Using $\mathrm{C}++$, a bespoke software has been developed to perform Monte Carlo simulations, and carry them out in parallel in order to reduce the run time. 100000 simulations were completed in 70 seconds using a computer with a dual core Intel i3 processor, and the convergence of the various statistics collected was achieved within these 100000 simulations. For instance, Figure 7 shows the convergence of the mean yearly number of service affecting system failures for various years.

\section{Convergence of the Mean Number of Failures Per Year}

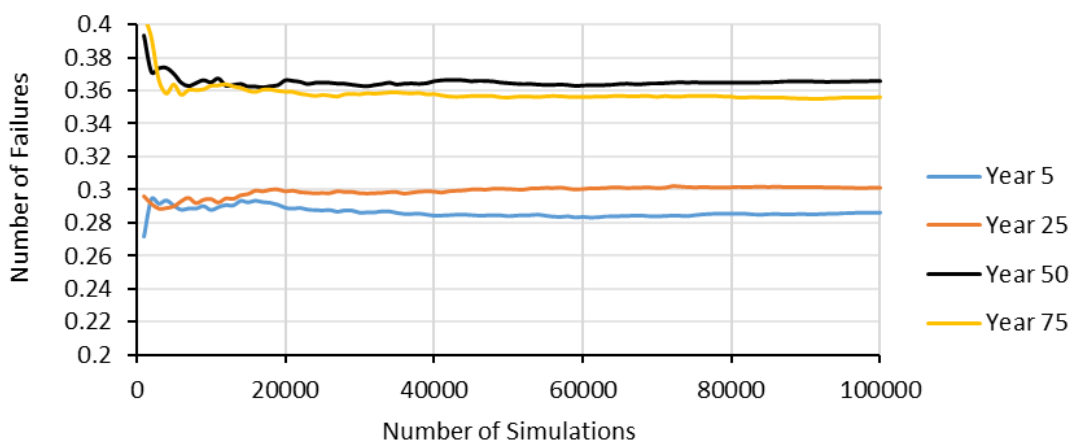

Figure 7. Convergence of the Mean Number of Failures per Year (With Opportunistic Maintenance)

This modelling approach can be adapted to any size of the OLE system. Analysing more components simply requires additional tokens to be added to the model, i.e. no additional places or transitions are needed, and therefore, the size of the model does not increase. However, increasing the size of the system increases the time taken to evaluate the model, since a greater number of processes will be modelled, represented by additional modes in some transitions. Figure 8 shows an illustration of the modelling time increase for 1000 simulations due to the increased number of components, which is the order of $\mathrm{O}\left(\mathrm{n}^{2}\right)$ complexity. In comparison, the modelling of the 2-mile section analysed in this 
paper, consisting of 364 components, for 100,000 simulations took 70 seconds, whereas a 16-mile section, consisting of around 3000 components, it took around 25 minutes.

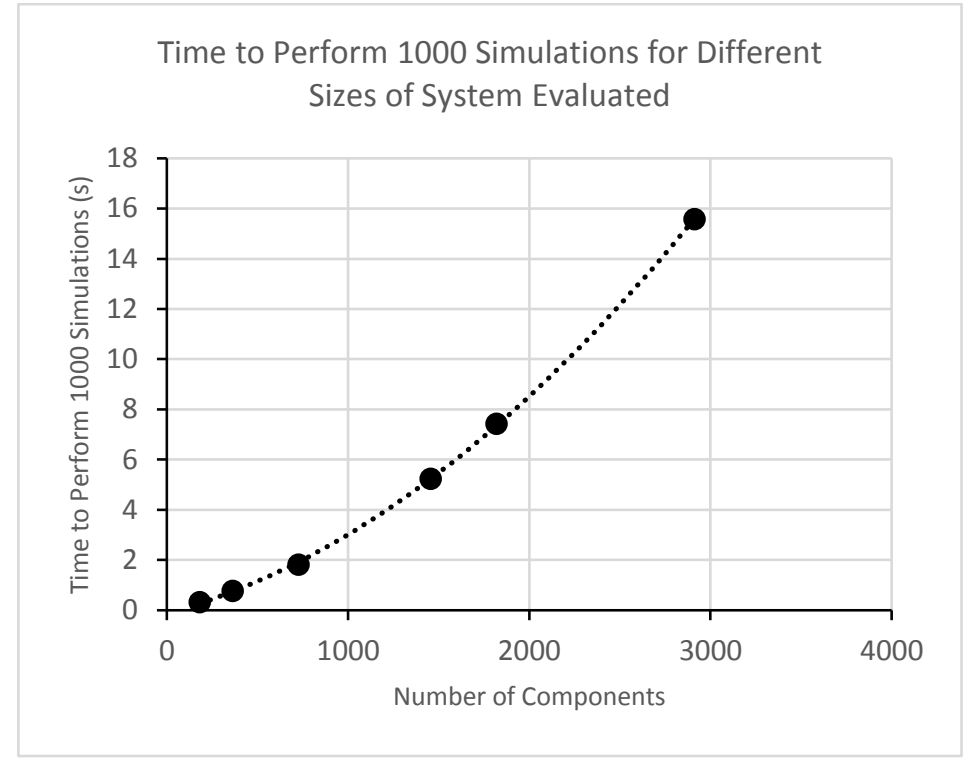

Figure 8. Illustration of the relationship between the modelling time and the number of components

A number of statistics were collected for the overall OLE system and for each component type in the access area studied. These statistics are related to the performance of the system or the components, such as the number of system failures, the amount of time a component spends in a degraded condition, the amount of scheduled maintenance visits to the access area, and the total costs, such as the maintenance costs and the delay costs due to service affecting failures. Note that due to confidentiality, all the costs given in the paper have been multiplied by a factor.

For example, Figure 9 shows the mean number of scheduled maintenance works for the catenary wire and the overall number of scheduled maintenance visits for the access area, for the maintenance strategy that considered opportunistic maintenance. It can be seen that the mean yearly number of maintenance works increases as the components age, and therefore the components are more likely to be maintained later in their life. After year 70 a renewal of the contact and catenary wires is scheduled. Therefore, the number of maintenance works for the catenary wire is reduced, as after the renewal the wire is in the new condition, and therefore less likely to require maintenance. Since maintenance of other OLE components is also scheduled to take place at the same time as the renewal of the catenary wire, there are fewer maintenance visits in the access area in that year. Note that the spike every 4 years for the number of maintenance visits to the access area coincides with the high level intrusive inspection interval, which is also considered as a maintenance visit, where any maintenance works are undertaken if required. There are fewer maintenance visits in the year following the high level inspection because the system is in a better condition where maintenance is less likely to be required. Note that the increased number of maintenance visits required during the first 2 years is due to early component issues, caused by installation errors. In comparison, Figure 10 shows the mean number of maintenance visits to the access area when opportunistic maintenance is not considered. It is clearly shown that far more maintenance visits are required each year.

In addition to the mean, other quantities, such as the maximum, minimum and interquartile range, are calculated in order to evaluate the levels of uncertainty that are associated with the cost and performance of the system over its lifecycle. Figure 11 shows various results describing the yearly cumulative total system cost for each year of simulation for the strategy that considered opportunistic 
maintenance. Note that the large step increase after 70 years is due to the cost of the large scale renewal undertaken.

Table 5 lists the statistics associated with the cumulative system costs for the 100 -year period modelled, with and without opportunistic maintenance. Note that the mean total cumulative cost was calculated to be approximately $20 \%$ larger if opportunistic maintenance is not undertaken. This is because opportunistic maintenance results in fewer maintenance visits and the component maintenance actions are undertaken sooner, which also reduces the number of failures. Figure 12 gives an insight into the distribution of the cumulative total system costs and its uncertainty for the strategy that considered opportunistic maintenance. Since the failure costs, which are lognormally distributed, outweigh the maintenance costs, it can be seen in Figure 12 that the costs are also lognormally distributed. Due to a large positive skew of this distribution, the median ( $f 1.606 \mathrm{million})$ is a more appropriate measure of the average expected total cost than the mean ( $\approx 1.770$ million).

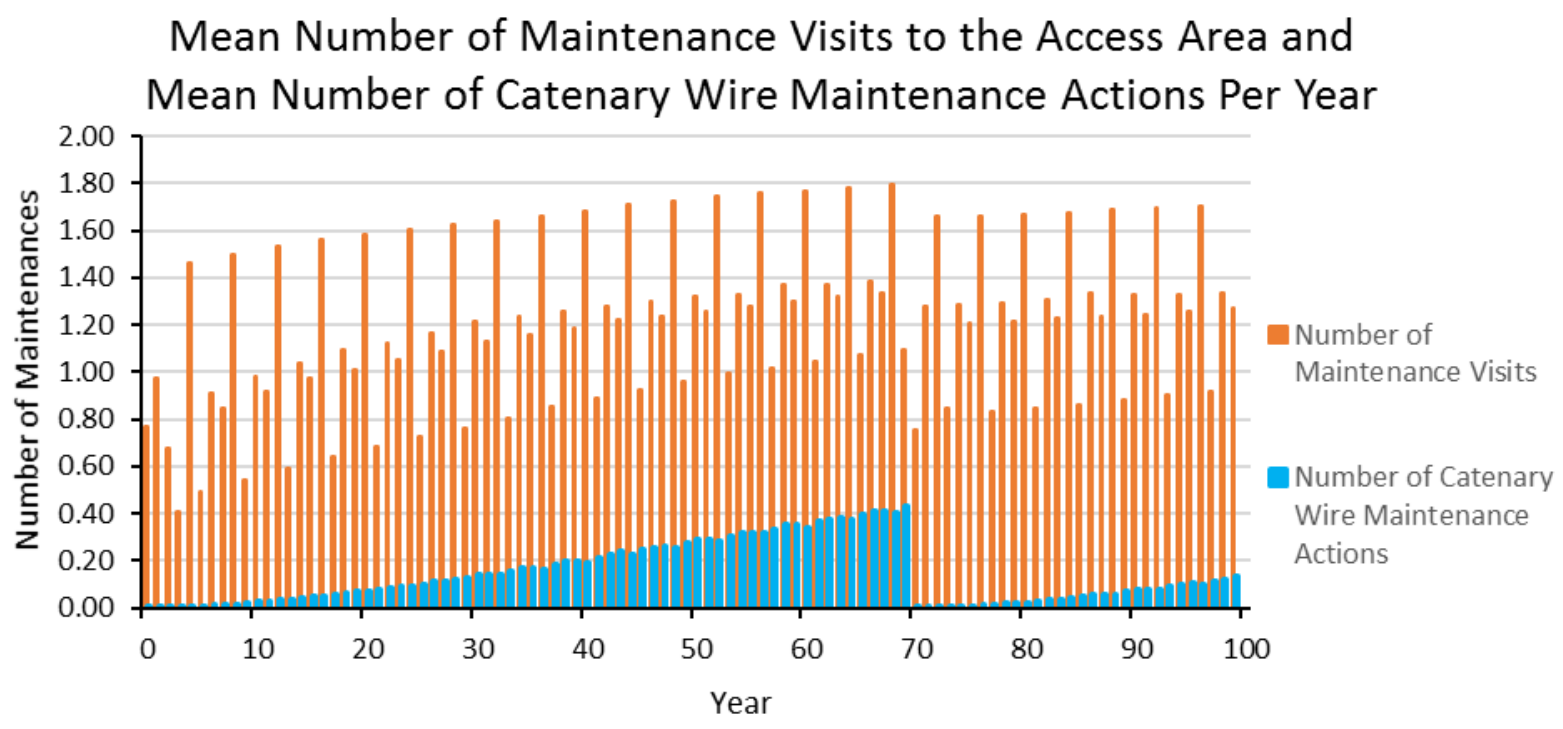

Figure 9. Mean Number of Maintenance Visits to the Access Area and Mean Number of Catenary Wire Maintenance Actions Per Year (With Opportunistic Maintenance)

\section{Mean Number of Maintenance Visits to the Access Area Per Year} (With No Opportunistic Maintenance)

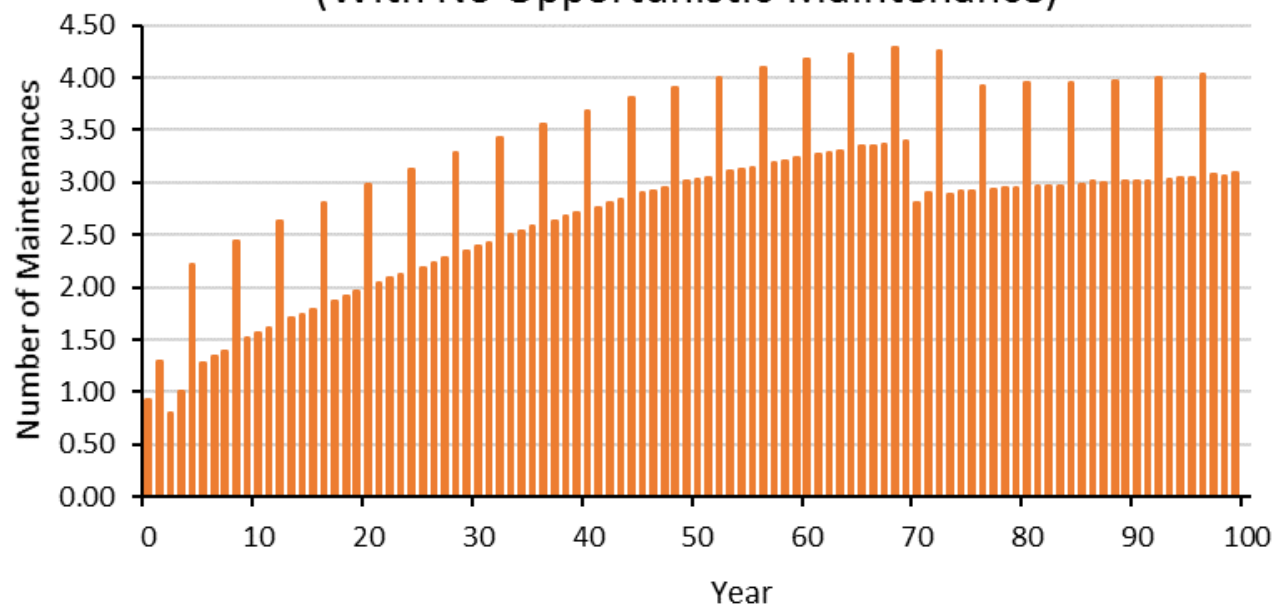

Figure 10. Mean Number of Maintenance Visits to the Access Area (Without Opportunistic Maintenance) 


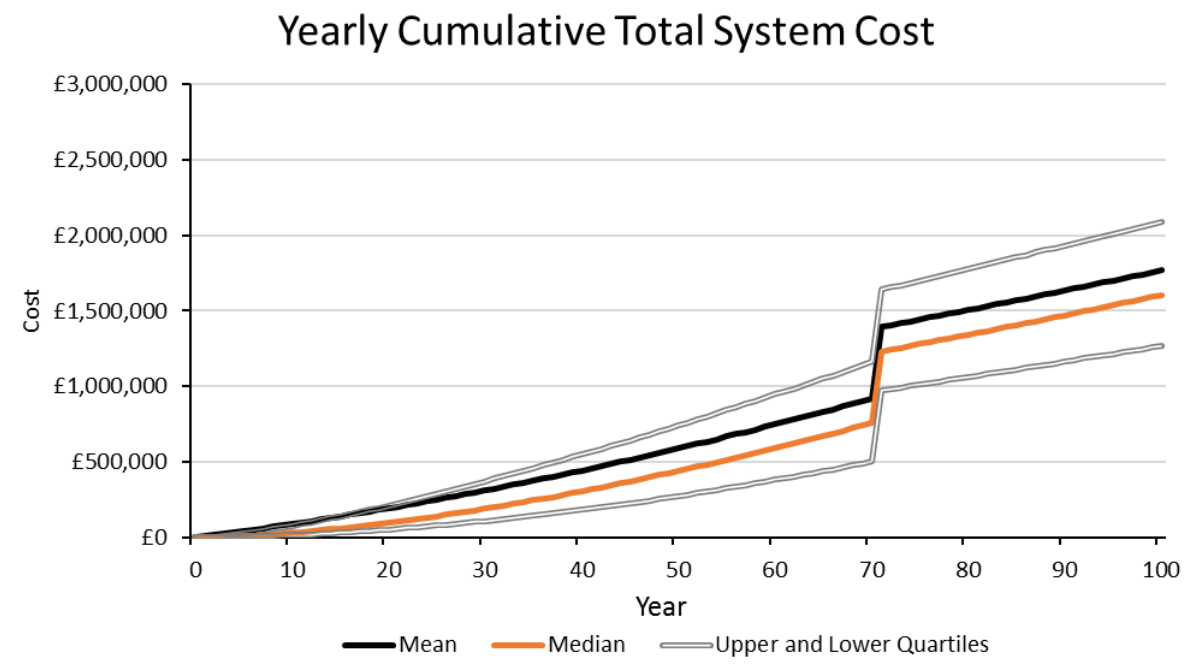

Figure 11. Yearly Cumulative Total System Cost (with Opportunistic Maintenance)

Table 5. Year 100 Cumulative Cost Statistics (With and Without Opportunistic Maintenance)

\begin{tabular}{|c|c|c|c|c|c|c|}
\hline & \multicolumn{2}{|c|}{ Total Cost } & \multicolumn{2}{|c|}{$\begin{array}{l}\text { Maintenance Cost } \\
\text { (including renewals) }\end{array}$} & \multicolumn{2}{|c|}{ Failure Cost } \\
\hline & $\begin{array}{l}\text { With Opp. } \\
\text { Maint. }\end{array}$ & $\begin{array}{c}\text { Without } \\
\text { Opp. Maint. }\end{array}$ & $\begin{array}{l}\text { With Opp. } \\
\text { Maint. }\end{array}$ & $\begin{array}{c}\text { Without } \\
\text { Opp. Maint. }\end{array}$ & $\begin{array}{l}\text { With Opp. } \\
\text { Maint. }\end{array}$ & $\begin{array}{c}\text { Without } \\
\text { Opp. Maint. }\end{array}$ \\
\hline Mean & $£ 1.770 \mathrm{M}$ & $f 2.108 \mathrm{M}$ & $£ 0.670 \mathrm{M}$ & $f 0.798 \mathrm{M}$ & $£ 1.100 \mathrm{M}$ & $f 1.310 \mathrm{M}$ \\
\hline Median & $£ 1.606 \mathrm{M}$ & f1.942 M & $£ 0.670 \mathrm{M}$ & f0.798 M & $£ 0.935 \mathrm{M}$ & f1.143 M \\
\hline Maximum & f7.110 M & f7.839 M & $£ 0.715 \mathrm{M}$ & $f 0.877 \mathrm{M}$ & f6.447 M & f7.065 M \\
\hline Minimum & $£ 0.704 \mathrm{M}$ & f0.847 M & $£ 0.628 \mathrm{M}$ & $f 0.724 \mathrm{M}$ & $£ 0.039 \mathrm{M}$ & $f 0.071 \mathrm{M}$ \\
\hline $\begin{array}{l}\text { Standard } \\
\text { Deviation }\end{array}$ & $£ 0.689 \mathrm{M}$ & f0.749 M & $£ 0.011 \mathrm{M}$ & $£ 0.017 \mathrm{M}$ & f0.689 M & $£ 0.749 \mathrm{M}$ \\
\hline $\begin{array}{l}\text { Upper } \\
\text { Quartile }\end{array}$ & f2.090 M & f2.477 M & $£ 0.678 \mathrm{M}$ & $£ 0.809 \mathrm{M}$ & f1.419 M & f1.679 M \\
\hline $\begin{array}{l}\text { Lower } \\
\text { Quartile }\end{array}$ & $£ 1.271 \mathrm{M}$ & $f 1.565 \mathrm{M}$ & $£ 0.663 \mathrm{M}$ & $f 0.787 \mathrm{M}$ & $£ 0.600 \mathrm{M}$ & $£ 0.766 \mathrm{M}$ \\
\hline $\begin{array}{l}\text { Inter } \\
\text { Quartile } \\
\text { Range }\end{array}$ & f0.819 M & $f 0.913 \mathrm{M}$ & $£ 0.014 \mathrm{M}$ & $£ 0.022 \mathrm{M}$ & f0.819 M & $f 0.913 \mathrm{M}$ \\
\hline
\end{tabular}

Overall, this set of different statistics provided allows decision makers to gain a better understanding of the expected performance and cost of the system over its whole lifecycle under a given maintenance strategy. Such results can be used to predict future maintenance volumes and budget required. The outputs can be obtained for the different component types individually or for the overall system. Similarly, alternative maintenance strategies, which involve different start time, duration and type of maintenance, inspection and renewals can also be tested in the model. 


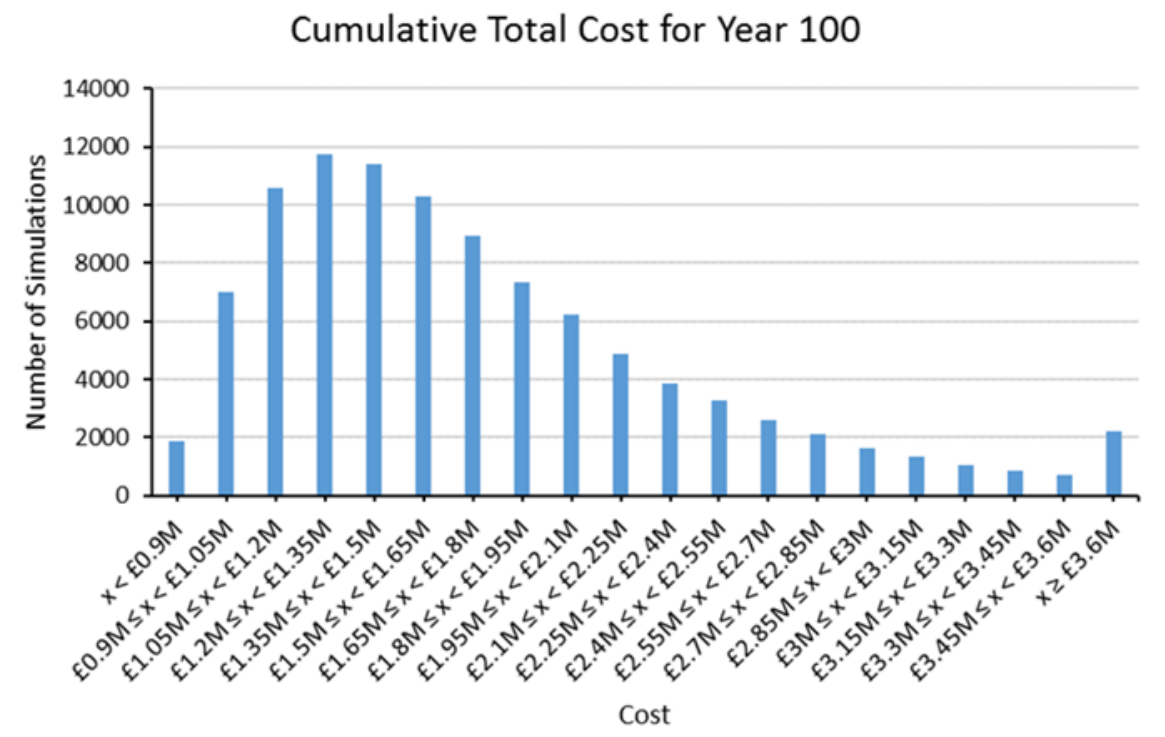

Figure 12. Distribution of Cumulative Total Costs in Year 100 (With Opportunistic Maintenance)

\section{Conclusion}

This paper has presented a modelling approach based on a stochastically timed High Level Petri Net method that simulates processes of degradation, failure, inspection and maintenance of the OLE system and its components. In this novel whole system modelling approach, different OLE component types and their instances on an OLE line are modelled simultaneously, and the dependencies between components are considered in terms of opportunistic inspection and maintenance policies. In addition, condition-based maintenance is modelled instead of commonly considered fixed-time OLE system maintenance. An example HLPN for the catenary wire is given to illustrate the approach of component model building, followed by a description of the whole system model.

The model is used to obtain various statistics associated with the cost and reliability of the system over its whole lifecycle, such as the mean number of failures per year or the mean number of maintenance visits per year, for the component types and the overall OLE system, and such as the mean total cost of failure and maintenance over the whole lifecycle. Such statistics and their uncertainty analysis can help to inform asset management decisions, when the investment required to deliver the level of performance desired by railway customers and regulators can be based on evidence from the analysis modelling results. Predicting future costs and maintenance volumes can improve procurement, and different renewal project options or maintenance strategies can be evaluated with the preference given for the option with the lowest whole lifecycle cost. Through comparing different maintenance strategies, the example analysis showed that opportunistic maintenance results in significant reductions in the total system cost and the number of required maintenance visits.

Future work could involve further analysis of probability distributions of times to reach degraded and failed states of components if more data becomes available over time. The degradation of one component type might influence the degradation of another component type (such as a degraded and seized registration equipment may result in an increased localised wear of the contact wire), and if this process could be evidenced by further data analysis, it could also be implemented in the HLPN by representing such dependencies between the component types. In addition, maintenance scheduling times and inspection intervals could be optimised using the HLPN model, in order to find maintenance 
and inspection strategies that result in the lowest lifecycle cost of the system without increasing the number of system failures.

\section{Acknowledgments}

The project is supported by Network Rail and the Engineering and Physical Sciences Research Council (EPSRC). The authors gratefully acknowledge the support of these organisations.

\section{References}

[1] Skinner, M., Kirwan, A., \& Williams, J. 2011. Challenges of developing whole life cycle cost models for Network Rail's top 30 assets. In IET and IAM Asset Management Conference 2011.

[2] British Standards, 1997. BS 5760: Part 23, Guide to Life Cycle Costing.

[3] RSSB, 2007. T346: Investigating the potential for improvements in electrification systems Summary report. s.l.

[4] Meier-Hirmer, C., Sourget, F., and Roussignol, M. 2006. Lifetime estimation of catenary components. In Proceedings of the European Safety and Reliability Conference, ESREL 2006, Estoril, Portugal, Safety and reliability for managing risk - Soares, C.G. and Zio, E. (eds); 2006 Taylor and Francis Group, London, 929-934

[5] Duque, O., Zorita, A.L., García-Escudero, L.A. and Fernández, M.A., 2009. Criticality determination based on failure records for decision-making in the overhead contact line system. Proceedings of the Institution of Mechanical Engineers, Part F: Journal of Rail and Rapid Transit, 223(5), 485-494.

[6] Chen, S. K., Ho, T. K., and Mao, B. H. 2007. Reliability evaluations of railway power supplies by fault-tree analysis. Electric Power Applications, IET, 1(2), p.161-172.

[7] Zorita, A.L., Duque, O., Fernández, M.A. and García-Escudero, L.A., 2010. Determination and optimization of the maintenance frequencies in the overhead contact line system. Journal of Transportation Engineering,136(11), 964-972.

[8] Ho, T. K., Chi, Y. L., Ferreira, L., Leung, K. K., and Siu, L. K. 2006. Evaluation of maintenance schedules on railway traction power systems. Proceedings of the Institution of Mechanical Engineers, Part F: Journal of Rail and Rapid Transit, 220(2), 91-102.

[9] Min, L. X., Yong, W. J., Yuan, Y., \& Yan, X. W. 2009. Multiobjective optimization of preventive maintenance schedule on traction power system in high-speed railway. In Reliability and Maintainability Symposium, 2009. RAMS 2009. Annual, 365-370.

[10] Prajapati, A., Bechtel, J. and Ganesan, S., 2012. Condition based maintenance: a survey. Journal of Quality in Maintenance Engineering, 18(4), pp.384-400.

[11] Ab-Samat, H. and Kamaruddin, S., 2014. Opportunistic maintenance (OM) as a new advancement in maintenance approaches: A review. Journal of Quality in Maintenance Engineering, 20(2), pp.98-121.

[12] Petri, C. A., 1962. Kommunikation mit automaten. PhD Thesis, University of Bonn.

[13] Dutuit, Y., Châtelet, E., Signoret, J.P. and Thomas, P., 1997. Dependability modelling and evaluation by using stochastic Petri nets: application to two test cases. Reliability Engineering \& System Safety, 55(2), pp.117-124. 
[14] Girault, C. and Valk, R., 2003. Petri nets for systems engineering: a guide to modeling, verification, and applications. Berlin, Springer Berlin Heidelberg.

[15] Andrews, J. 2012. A modelling approach to railway track asset management. Proceedings of the Institution of Mechanical Engineers, Part F: Journal of Rail and Rapid Transit, p.56-73.

[16] Jensen, K. and Kristensen, L.M., 2009. Coloured Petri nets: modelling and validation of concurrent systems. Dordrecht, Springer Science \& Business Media.

[17] Volovoi, V., 2004. Modeling of system reliability Petri nets with aging tokens. Reliability Engineering \& System Safety, 84(2), pp.149-161.

[18] British Standards, 2004. BS ISO/IEC 15909-1:2004+A1:2010 Systems and software engineering High-level Petri nets

[19] Kiessling, F., Puschmann, R., Schmieder, A. and Schneider, E., 2009. Contact Lines for Electric Railways. Erlangen, Publicis.

[20] Dufourd, C., Finkel, A. and Schnoebelen, P., 1998 . Reset nets between decidability and undecidability. In International Colloquium on Automata, Languages, and Programming, Springer Berlin Heidelberg, 103-115.

[21] Le, B., Andrews, J., 2016. Modelling wind turbine degradation and maintenance. Wind Energy Volume 19 (4), 571-591

[22] Network Rail, 2011. NR/L2/ELP/21087 Specification of maintenance frequency and defect prioritisation of $25 \mathrm{kV}$ overhead line electrification equipment. Internal NR documentation. 